\title{
TRANSFORMAÇÃO DIGITAL NA INDÚSTRIA DE ALIMENTOS: PROPOSTA DE FRAMEWORK APLICADO
}

\section{DIGITAL TRANSFORMATION IN THE FOOD INDUSTRY: A FRAMEWORK PROPOSAL}

\author{
Alexsander Canaparro \\ Mestre em Administração \\ Escola de Gestão e Negócios da Universidade do Vale do Rio dos Sinos -UNISINOS \\ Porto Alegre- RS- Brasil \\ canaparro.mba@gmail.com \\ Angelito Dornelles da Rocha \\ Mestre em Direito \\ Universidade do Vale do Rio dos Sinos - UNISINOS \\ Porto Alegre - RS \\ ar@angelitorocha.com.br \\ Marcelo André Machado \\ Doutor \\ Escola de Gestão e Negócios da Universidade do Vale do Rio dos Sinos - UNISINOS \\ Porto Alegre- RS- Brasil \\ mmachado@unisinos.br \\ José Carlos da Silva Freitas Junior \\ Doutor \\ Escola de Gestão e Negócios da Universidade do Vale do Rio dos Sinos - UNISINOS \\ Porto Alegre- RS- Brasil \\ josecf@unisinos.br
}

Resumo: O processo de Transformação Digital (TD) é um desafio imposto por uma realidade de mercado onde a competitividade é fator chave para as organizações atingirem desempenhos superiores. As empresas devem integrar gradualmente novas tecnologias em seu processo de criação de valor por meio do desenvolvimento de projetos organizacionais apropriados. A TD pode ser considerada um processo e não um evento - ou seja, apoiando uma etapa a outra e não em eventos individuais e deve impactar de forma significativa o modelo de negócio. Portanto, não se deve confundir estratégia de Tecnologia de Informação (meio) com estratégia de TD (fim). Porém, os desafios para iniciar o processo de TD são inúmeros, sendo necessário definir por onde e como começar, quais tecnologias adotar, entre outros. Dado tamanha complexidade, o presente artigo aplicado tem por objetivo apresentar um framework contemplando as etapas necessárias para a implementação da transformação digital na em indústria alimentícia DOCE SABOR (nome fictício). Para tanto, utilizou-se o método Design Science Research (DSR). Assim, o presente artigo aplicado estruturou-se com base nos passos do DSR. Dentre os resultados e contribuições destaca-se que o framework apresentado contempla as etapas necessárias para a implementação da TD na indústria DOCE SABOR. Além disso, este estudo contribui com a literatura apresentando novos estudos e conhecimentos gerados ao longo do processo do DSR, bem como a metodologia em si, com as etapas necessárias para a TD em uma indústria, que podem ser seguidas e/ou adaptadas por gestores de uma forma geral.

Palavras-chave: Transformação digital. Framework. Design science research. Indústria.

Abstract: The Digital Transformation (DT) process is a challenge imposed by a market reality where competitiveness is a key factor for organizations to achieve superior performance. Companies must gradually integrate new technologies into their value creation process by developing appropriate organizational projects. TD can be considered a process rather than an event - that is, supporting one step to another rather than individual events and should significantly impact the business model. Therefore, one should not confuse IT strategy (means) with TD strategy (end). However, the challenges to start the TD process are numerous defining where and how to start, which technologies to adopt, among others. Given such complexity, this applied article aims to a framework contemplating the necessary steps for the implementation of digital transformation in the food industry DOCE SABOR (fictitious name). To this end, the Design Science Research (DSR) method was used. Thus, this article was structured based on the DSR steps. Among the results and contributions, it is noteworthy that the framework presented contemplates the necessary steps for the implementation of TD in the industry DOCE SABOR. Moreover, this study contributes to the literature by presenting new studies and knowledge generated throughout the process of the DSR, as well as the methodology itself, with the necessary steps for TD in an industry, which can be followed and/or adapted by managers in general.

Keywords: Digital transformation. Framework. Design science research. Industry.

Cite como

American Psychological Association (APA)

Canaparro, A., Rocha, A. D., Machado, M. A., \& Freitas Junior, J. C. S. Transformação digital na indústria de alimentos: proposta de framework aplicado. Revista Inovação, Projetos e Tecnologias - IPTEC, São Paulo, 9(2), 289-308. https://doi.org/10.5585/iptec.v9i2.20819. 


\section{Introdução}

Uma transformação digital (TD) geralmente envolve dois tipos de mudanças. A primeira, uma inovação do modelo de negócios, por meio da introdução de produtos e serviços habilitados digitalmente. A segunda está relacionada ao aprimoramento operacional, pelo qual as tecnologias e formas de trabalhar são aplicadas para a melhora do desenvolvimento e entrega de projetos (Koeleman, Ribeirinho, Rockhill, Sjödin, \& Strube, 2019).

Os benefícios da transformação digital são múltiplos e incluem aumentos de vendas ou produtividade, inovações na criação de valor assim como novas formas de interação com os clientes. Para que a transformação digital tenha retornos satisfatórios é pertinente haver uma formulação de estratégia digital que sirva como conceito central para integrar toda a coordenação, priorização e implementação de transformações digitais dentro de uma empresa (Matt, Hess, \& Belian, 2015).

As empresas que pretendem se transformar precisam integrar gradualmente novas tecnologias em seu processo de criação de valor por meio do desenvolvimento de projetos organizacionais apropriados. A transformação digital requer o desenvolvimento de novos modelos de negócios híbridos (Endres, Stoiber, \& Wenzl, 2019). Nesse tipo de negócio híbrido, uma empresa precisa gerenciar dois caminhos separados de criação de valor: exploitation e exploration, o primeiro refere-se é a criação de valor a partir de recursos existentes na organização, enquanto o segundo é a criação de um novo valor através da inovação (Margiono, 2020). Para ilustrar, destaca-se a Netflix que inicialmente fez uma exploitation do mercado existente oferecendo serviços de aluguel de DVD e, após, exploration - exploração de novos mercados, por meio da introdução de streaming nos mercados nacional e internacional (Margiono, 2020).

Nota-se, portanto, que o processo de transformação digital é uma realidade de mercado, mas muitas empresas ainda estão no processo de entender suas vantagens e os impactos dessa mudança. Pois, atualmente, uma série de tecnologias emergentes estão disponíveis (internet das coisas, big data, cloud computing, entre outras). Entretanto, transformar-se digitalmente está muito além da simples implantação de novas tecnologias (Koeleman et al., 2019).

O presente estudo foi desenvolvido tendo como objeto de análise uma indústria alimentícia de candies. A fim de preservar a identidade da empresa, para este estudo será utilizado o nome fictício de DOCE SABOR. Atualmente, a empresa possui duas unidades produtivas, uma na cidade de Lajeado, no Rio Grande do Sul e outra na cidade de Vitória de Santo Antão, em Pernambuco. São 33,5 mil metros quadrados de área construída. A produção 
alcança 2,6 milhões de quilos produzidos mensalmente. São atendidos mais de cinquenta países, com um portfólio em torno de 200 itens.

Diante disso, a empresa definiu como principais elementos da transformação digital, os seguintes pilares: "experiência do cliente", "processos operacionais" e "modelo de negócios". Um dos grandes desafios da empresa e atual dilema é como e quais ferramentas e/ou metodologias devem utilizar para percorrer essa trajetória - sobretudo, como garantir que ela será vitoriosa ao final.

Neste contexto, o presente artigo aplicado tem por objetivo apresentar um framework contemplando as etapas necessárias para a implementação da transformação digital na empresa DOCE SABOR. Para tanto, foi utilizado como método o Design Science Research (DSR) que norteou a estrutura do texto, que tem como passo inicial a revisão de literatura apresentada na seção 2 a seguir, e a partir da seção 3 o desenvolvimento da pesquisa é apresentado seguindo os passos metodológicos utilizados.

\section{Revisão da literatura}

A transformação digital pode ser definida como um processo que visa melhorar uma organização, desencadeando mudanças significativas em suas propriedades por meio de combinações de tecnologias de informação, computação, comunicação e conectividade (Vial, 2019). Ela se embasa em diversas tecnologias e processos para garantir uma melhor criação de valor em benefício de clientes e empresas (Margiono, 2020). Em um sentido amplo, a transformação digital se trata como uma integração de tecnologias digitais e processos de negócios em uma economia digital (Liu, Chen, \& Chou, 2011).

A influência da transformação digital implica três aspectos organizacionais: (1) de fora, com a melhoria da experiência do cliente e a mudança de todo o seu ciclo de vida; (2) no interior, o impacto sobre os objetivos de negócios, liderança básica e estruturas hierárquicas e; (3) em geral, quando todas as seções de negócios são influenciadas, geralmente levando a modelos de negócios completamente novos (Hess, Matt, Benlian, \& Wiesböck, 2016).

A transformação digital afeta todos os setores da sociedade, em particular o setor econômico, sendo um processo que passa por etapas, apoiando uma etapa a outra e não em eventos individuais (Liu et al., 2011). As organizações possuem a oportunidade de mudar radicalmente seus modelos de negócios por meio de novas tecnologias digitais como: redes sociais, big data, internet das coisas e blockchain. As mudanças envolvem operações, produtos 
e processos, assim como, estruturas organizacionais, haja vista a necessidade de as organizações criarem práticas de gestão para realizar essas complexas transformações (Ziyadin, Suieubayeva, \& Utegenova, 2020).

Organizações que implementaram com sucesso tecnologias digitais e formas de trabalho tinham em comum cinco práticas, quais sejam: (1) foco na fixação de "pontos de dor" e não na instalação de soluções de TI (tecnologia de informação); (2) implementação de digitalização que promovam a colaboração; (3) requalificação e reestruturação de equipes; (4) ajustes das linhas de base do projeto para capturar valor e; (5) conexão de projetos para gerar impacto em toda a organização (Koeleman et al., 2019).

O foco na fixação de pontos de dor, visa primeiro identificar as mudanças operacionais que melhorarão o desempenho e depois segue para a definição de quais casos de uso digital que possibilitará essas mudanças operacionais. Desta forma, será possível concentrar cada caso de uso de tecnologia a uma necessidade real de negócios (Koeleman et al., 2019). Os autores destacam que é recomendável que a implementação de casos de uso digital promova a colaboração entre os vários grupos e pessoas que colaboram com a organização, reduzindo retrabalhos e aumentando a qualidade de determinados serviços, por exemplo.

As estratégias de transformação digital devem estar alinhadas com outras estratégias de negócios. Não se confunde a estratégia de TI com a estratégia de Transformação Digital. Esta é focada na transformação de produtos, processos e aspectos organizacionais devido às novas tecnologias, aquela visa a gestão da infraestrutura de TI dentro da organização, com impacto limitado na condução de inovações no desenvolvimento do negócio (Hanelt, Bohnsack, Marz, \& Marante, 2021; Matt et al., 2015).

O escopo da estratégia de transformação digital inclui atividades digitais na interface com ou totalmente ao lado dos clientes, como tecnologias digitais como parte de produtos de usuário final. Nesse sentido, as estratégias de transformação digital têm certos elementos em comum que podem ser atribuídos a quatro dimensões essenciais: (1) uso de tecnologias; (2) mudanças na criação de valor; (3) mudanças estruturais e; (4) aspectos financeiros. Quanto ao uso de tecnologias, se trata da abordagem da atitude da empresa em relação às novas tecnologias, assim como sua capacidade de exploração das mesmas. Dessa forma, uma organização precisa decidir se quer se tornar líder de mercado em termos de uso de tecnologia com capacidade de criar padrões tecnológicos próprios, ou se prefere recorrer a padrões já estabelecidos, percebendo as tecnologias como meios para cumprir as operações de negócios (Matt et al., 2015; Singh, Klarner, \& Hess, 2020). 
No que tange a mudanças na criação de valor, muitas vezes isso ocorre quando novas tecnologias são usadas, se tratando de um impacto das estratégias de transformação digital nas cadeias de valor das empresas, ou seja, o quanto as novas atividades digitais se desviam do core business. Outros desvios oferecem oportunidades para expansão e enriquecimento do portfólio de produtos e serviços, mas muitas vezes são acompanhados por uma necessidade mais forte de diferentes competências tecnológicas relacionadas a produtos e riscos devido a menor experiência no novo campo (Matt et al., 2015).

Quanto às mudanças esperadas, a transformação digital as causará de forma limitada ou substancial. Quando a mudança for limitada, pode ser mais razoável integrar as novas operações às estruturas corporativas já existentes, enquanto, para mudanças mais substanciais, seria melhor criar uma subsidiária dentro da organização (Gobble, 2018; Koeleman et al., 2019).

As dimensões mencionadas anteriormente devem ser consideradas conforme aspectos financeiros, que incluem a urgência de uma empresa de agir devido a um negócio principal em declínio e sua capacidade de financiar um esforço de TD. É o aspecto financeiro que dirigirá a transformação digital bem como será uma força delimitadora para ela (Matt et al., 2015). Neste sentido, Margiono (2020) sugere dois caminhos contingentes de transformação digital, um dos caminhos é o chamado caminho ofensivo de TD, onde a empresa precisa avançar rapidamente para lançar estratégias para garantir sua continuidade como líderes. Esse caminho permite que a empresa ofereça imediatamente novos produtos para novos mercados e se coloquem frente a frente com concorrentes. Em uma primeira fase, os processos de criação de valor não estão alinhados e as startups adquiridas oferecem uma proposta de valor diferente da adquirente. Aos poucos, a empresa adquirente tem que integrar a estrutura da startup à sua, começando a digitalização dos produtos existentes e começando a transferência de recursos da startup para a empresa que a adquiriu (Margiono, 2020).

Outro caminho é o defensivo, onde as empresas preferem lançar uma estratégia de transformação digital para defender e atender ao mercado existente através da digitalização de seus produtos existentes. Com o desenvolvimento de recursos digitais suficientes, essas empresas diversificam os produtos e oferecem novo valor ao mercado. As empresas que tomam um caminho defensivo precisam garantir que sua estrutura existente possa absorver a digitalização (Gobble, 2018; Margiono, 2020).

Portanto, a transformação digital é mais do que adotar soluções tecnológicas. Além disso, para ser bem-sucedida requer um começo com a clara definição de como o digital criará valor para o negócio. Durante esta transformação, para que haja um aumento significativo de 
produtividade, as lideranças da organização devem gastar tanto tempo em mudanças organizacionais quanto em tecnologia. A garantia do sucesso sustentado de uma transformação digital é dar prioridade aos esforços para definição de novos produtos e serviços, assim como a digitalização dos modelos operacionais (Koeleman et al., 2019).

Pode-se dizer que a transformação digital possui as seguintes fases: (1) iniciação, que é a compreensão das aberturas de digitalização, perigos e efeitos; (2) ideação, pensando em medidas de transformação como alternativas para os negócios; (3) avaliação dos níveis de preparação digital e identificando gaps; (4) compromisso com a comunicação e visão, incorporando os indivíduos fundamentais e; (5) implementação e sustentabilidade (Liu et al., 2011).

Para lidar com a transformação digital, se faz necessário o desenvolvimento de um plano de médio e longo prazo alinhado com a estratégia do negócio e com etapas bem definidas. Pois mais de um terço dos executivos, quando questionados sobre as principais barreiras para alcançar o potencial digital do negócio, citam a falta de uma estratégia digital clara. Neste sentido, as principais etapas e práticas recomendas por White (2020) estão no quadro 1.

\section{Quadro 1.}

Fase da Estratégia

\begin{tabular}{|l|l|}
\hline Fase & \multicolumn{1}{c|}{ Definição } \\
\hline $\mathbf{1}$ & $\begin{array}{l}\text { Alinhe-se com o porquê da transformação digital - parte do problema com o termo "transformação } \\
\text { digital" é que significa muitas coisas para muitas pessoas - e são todas diferentes. O ponto central do } \\
\text { processo não está na tecnologia, ela não deve preceder a estratégia de negócio. O sucesso de um processo } \\
\text { de transformação digital passa pela identificação das necessidades e metas de negócio. }\end{array}$ \\
\hline $\mathbf{2}$ & $\begin{array}{l}\text { Prepare-se para a mudança cultural - o apoio e entusiasmo da diretoria pela transformação digital são } \\
\text { essenciais para a mudança cultural acontecer - "não é a tecnologia o centro da transformação digital, são } \\
\text { os humanos". }\end{array}$ \\
\hline $\mathbf{3}$ & $\begin{array}{l}\text { Comece pequeno, mas estratégico - a transformação digital é uma jornada, não um evento. E identificar } \\
\text { o primeiro projeto de "prova de conceito" é crucial. É o que definirá o terreno para iniciativas futuras - } \\
\text { e ajudará a obter a adesão de líderes e equipes. }\end{array}$ \\
\hline $\mathbf{4}$ & $\begin{array}{l}\text { Implementação de tecnologia de mapeamento - com a base estabelecida nas três primeiras etapas, a } \\
\text { tecnologia se torna uma ferramenta necessária, ou alavanca, para ajudá-lo a alcançar os resultados de } \\
\text { negócios desejados. Atenção e cuidado com as novas tecnologias, pois elas por si só não vão resolver o } \\
\text { seu problema - novas tecnologias + antigas operações = antigas operações caras. }\end{array}$ \\
\hline $\mathbf{5}$ & $\begin{array}{l}\text { Procure parceiros e experiências - ao revisar as opções e parceiros de tecnologia, tenha em mente a visão } \\
\text { futura do negócio - lembre-se, a transformação digital é uma jornada, não um evento. }\end{array}$ \\
\hline $\mathbf{6}$ & $\begin{array}{l}\text { Reúna feedback e refine conforme necessário - defina claramente os principais indicadores de } \\
\text { desempenho (KPIs) para cada projeto. Certifique-se de que todas as partes estejam cientes e sejam } \\
\text { responsáveis pelo que precisa ser entregue para considerar o projeto um sucesso. }\end{array}$ \\
\hline
\end{tabular}




\begin{tabular}{|l|l|}
\hline Fase & \multicolumn{1}{|c|}{ Definição } \\
\hline 7 & $\begin{array}{l}\text { Dimensionar e transformar - conforme a transformação digital avança, novas maneiras de melhorar as } \\
\text { conexões entre produtos, processo e pessoas vão surgindo. Considere as oportunidades de escalar } \\
\text { horizontalmente - aplicando estratégias semelhantes a vários locais - e verticalmente conectando } \\
\text { tecnologias adicionais. }\end{array}$ \\
\hline
\end{tabular}

Fonte: Adaptado de White (2020).

Para Liu et al. (2011), o processo de transformação digital deve acontecer de forma escalonada. Para tanto, algumas fases precisam ser consideradas/mensuradas, quais sejam: (1) realidade digital, onde o atual modelo de negócios da organização é delineado ao lado de um exame do que se objetiva, isso dará uma ideia da realidade digital para a organização em diversos territórios; (2) aspiração digital, que há a elaboração de metas em relação à transformação digital. Os objetivos se identificam com o tempo, contas, espaço e qualidade; (3) potencial digital, onde são reunidas melhores práticas e agentes capacitados para a transformação digital; (4) ajuste digital, que ganha uma base nas escolhas para o plano de modelo de negócio digital, que são avaliadas para decidir o ajuste digital com o modelo de negócio atual. Isso garantirá que se satisfaça as necessidades dos clientes e que as metas do negócio sejam alcançadas; por fim, (4) integração digital, onde o uso digital incorpora a conclusão e o uso do modelo de negócio digital. Com isso, o uso digital incorpora o plano de uma experiência digital do cliente e a organização de criação do que se espera com a digitalização.

Seguindo o roteiro de implementação do processo de transformação digital, Leipzig et al. (2017) sugerem um framework denominado modelo para inicialização da digitalização. O modelo foi desenvolvido tendo como base conceitual o ciclo de PDCA (Plan, Do, Check e Action), conforme demostrado na Figura 2. 


\section{Figura 2.}

Modelo Para Inicialização da Digitalização

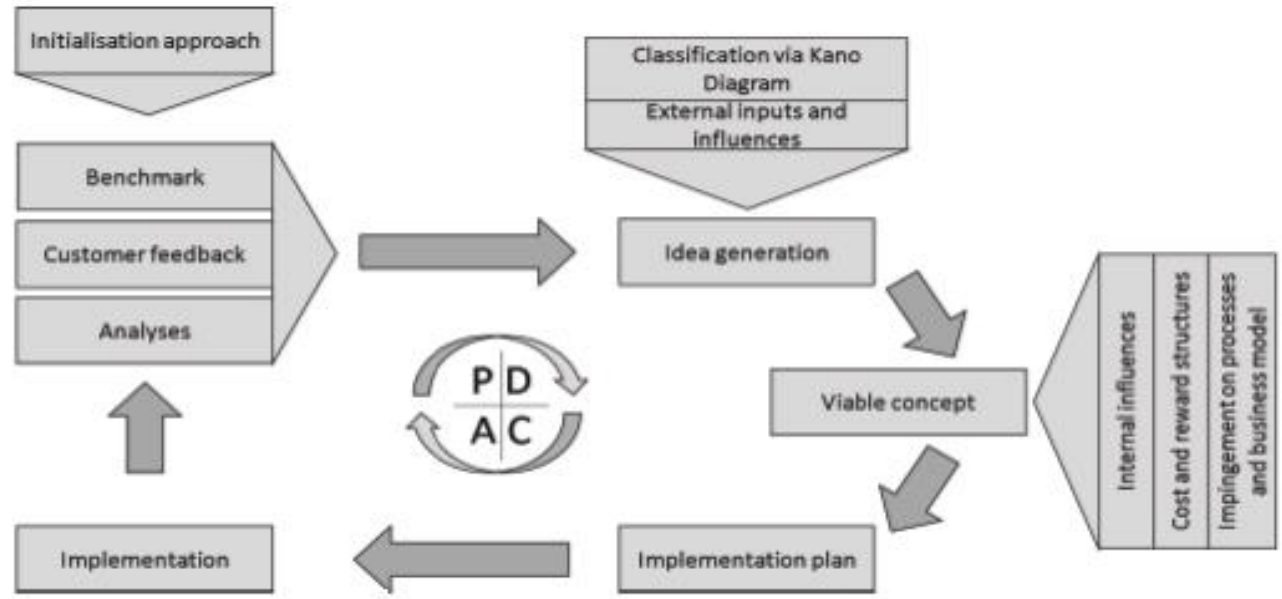

Fonte: Adaptado de Leipzig et al. (2017).

Para aquelas empresas que já iniciaram o processo, segundo Azhari, Faraby, Rossmann, Steimel, \& Wichmann (2014) citado por Leipzig et al. (2017), é possível avaliar o grau de maturidade que a empresa se encontra na jornada de transformação digital. Isso é possível, através do modelo de maturidade para a transformação digital. Esse modelo é composto por oito dimensões de digitalização e cinco níveis de maturidade.

\section{Método}

O método utilizado para o desenvolvimento deste caso foi o Design Science Research (DSR), por ser um método de pesquisa coerente e organizado assegura-se o rigor da pesquisa, a credibilidade dos resultados e das respostas ao problema estudado (Lacerda, Dresch, Proença, \& Antunes, 2013). A escolha do DSR ainda pode ser justificada através da sua apresentação, que é baseada e estruturada em uma realidade, além de sua capacidade de proporcionar maior validação e sensação de segurança quanto a eficácia do estudo frente aos contextos nos quais é desenvolvido (Anderson \& Shattuck, 2012).

Além disso, a escolha deste método levou em conta a necessidade de uma futura aplicação do estudo realizado e uma busca de sentido do mesmo para além do universo acadêmico, o método escolhido para esse trabalho foi o Design Science Research (DSR). Esse método visa a geração de algum tipo de artefato, solução, metodologia ou procedimento para problemas novos e práticos dentro de diferentes contextos (Freitas, Machado, Klein, \& Freitas, 2015). 
Assim, esta pesquisa se ocupou do desenvolvimento de artefato, considerando a subdivisão trazida por Vaishnavi, Kuechler e Petter (2019), de um framework como solução para o problema encontrado. A ideia fundamental é ter um guia que possa ajudar na otimização dos processos de transformação digital.

O método do Design Science Research tem, portanto, como uma de suas premissas a ação do pesquisador na realidade de estudo, dessa forma, ultrapassando a simples descritividade de fenômenos (Lacerda et al., 2013). Logo, o DSR deve seguir uma série de procedimentos que irão culminar na construção e apresentação de uma solução ou aprimoramento de algum tipo de problema, detalhados na figura 1 que ilustra as etapas do processo do método em questão:

\section{Figura 1.}

\section{Etapas da DSR}

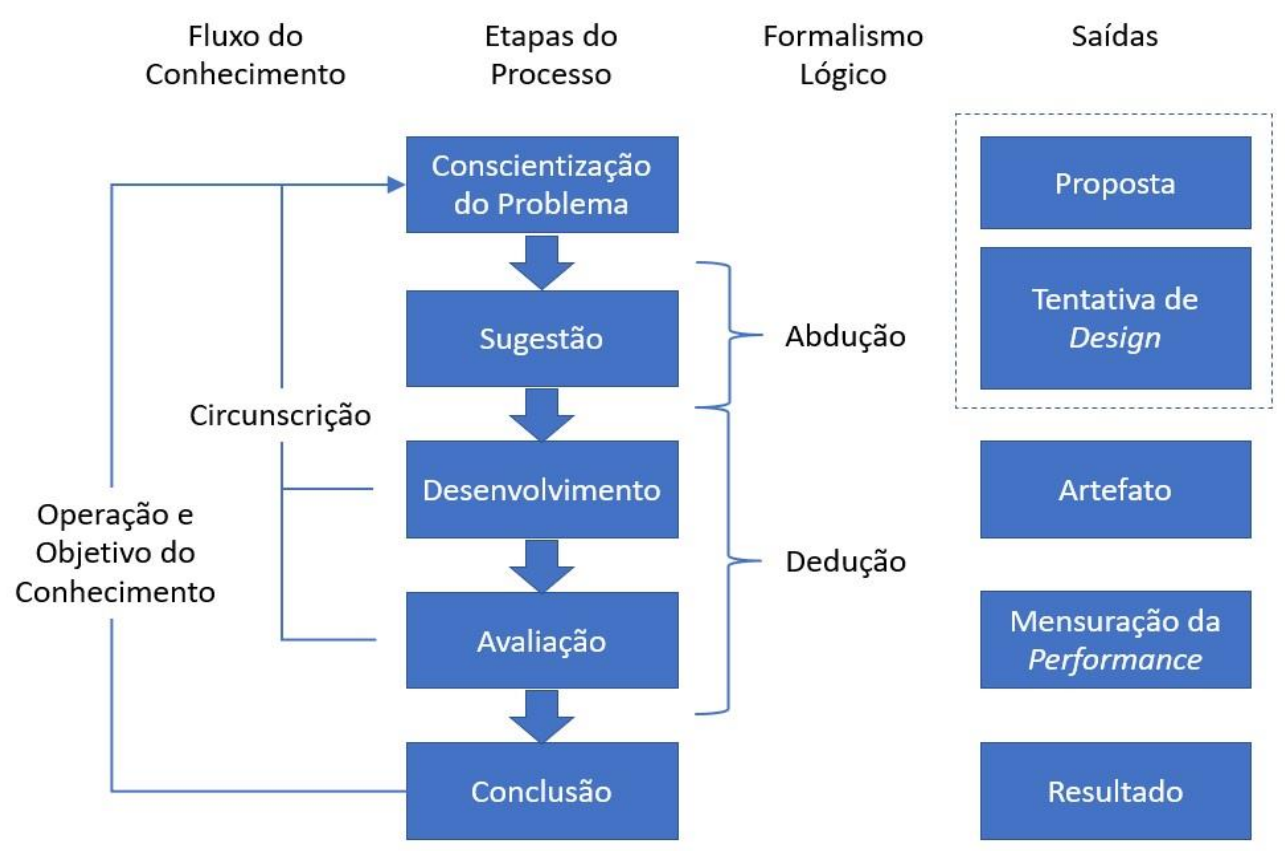

Fonte: Adaptado de Freitas et al. (2015).

Dentro da ordem dos procedimentos, a primeira etapa que deve ser executada é a de compreensão e conscientização em relação ao problema, na qual vai se buscar compreender o máximo possível sobre o contexto em que se vai atuar. Para isso, além da revisão de literatura, foram feitas reuniões com gestores da empresa que serão descritos no item 4.2. Posteriormente, com um maior aprofundamento sobre o tema, o método demanda o desenvolvimento de sugestões para solucionar os tipos de problemas que foram compreendidos, etapa que também 
pode ser vista como a geração de modelos de tentativa de algum tipo de artefato que possa vir a contribuir dentro da realidade do problema. Após, o método demanda o desenvolvimento artefato a ser considerado como a melhor alternativa para a possível melhoria ou solução do caso em questão. Por se tratar de uma solução, ainda há fases de testagem que funcionam como uma avaliação para possíveis correções ou mudanças de sua aplicação e eficiência antes da entrega final do resultado, para isso foi realizado um focus group (grupo focal) com executivos, conforme destacados na seção 7, avaliação (Freitas et al., 2015; Manson, 2006).

É importante ressaltar que a presente pesquisa atende o conceito de "classes de problemas", o que vai permitir uma maior aplicação e avanço do conhecimento adquirido através da DSR sobre determinado contexto (Lacerda et al., 2013), uma vez que o desafio da transformação digital é presente em várias organizações.

Assim, esta pesquisa, ao seguir as etapas lógicas da DSR, passou pela fase inicial de conscientização e compreensão do problema ao fazer uma completa e ampla análise dos conceitos que são definidores dos rumos do estudo, aqui sendo a transformação digital e o contexto da indústria (Lacerda et al., 2013; Manson, 2006).

Assim, seguindo os passos do DSR, o presente estudo está estruturado de acordo com cada etapa, onde são detalhados todos os procedimentos metodológicos desde a coleta e análise de dados e resultados que serão descritos a partir do item 3.

\subsection{Procedimentos de coleta de dados}

Essa pesquisa contou, primeiramente, com uma revisão sistemática da literatura em relação à comunicação, gestão de conhecimento e inovação. As bases consultadas para busca de artigos e livros foram encontrados, majoritariamente, no servidor EBSCOhost. As pesquisas buscaram dar uma maior importância para a data de publicação dos artigos, uma vez que os temas explorados aqui, apesar de serem conceitos clássicos, são efervescentes e dispõem de grande quantidade de material.

Posteriormente, compreendeu-se o contexto do problema encontrado através da análise de dados e materiais descritivos sobre organizações varejistas. E, a partir dos dados obtidos nos dois primeiros processos, executou-se outros dois movimentos para coleta de dados: entrevistas semiestruturadas com base em um questionário já proposto e validado, e análise documental.

Esses dois procedimentos para arrecadação das informações das organizações e equipes pesquisadas são os que apresentaram uma melhor condição para a representação da realidade, uma vez que a entrevista se presta a obter informações sobre determinado assunto por meio de 
uma conversa profissional e, esta, quando semiestruturada, apresenta algumas partes preestabelecidas, além de trazer à tona outros itens que tangem o assunto, mas podem ser discutidos de maneira mais livre. Segundo Barriball e While (1994), com esse tipo de técnica, pode-se esclarecer, obter e captar melhor a vivência subjetiva dos sujeitos.

Já com relação à análise documental, pode-se dizer que tem base em dados de fontes primárias - compostas por documentos originais gerados pelo pesquisador - e secundárias elementos que estão disponíveis para uso, como livros, revistas, artigos e outros (Barriball \& While, 1994). Dessa forma, buscamos conhecer e explorar o contexto de estudo em profundidade para que a posterior criação do artefato seja eficaz.

\subsection{Procedimentos de análise dos dados}

Todos os procedimentos para a coleta de dados, desde a análise documental até as entrevistas foram analisados posteriormente. Essa análise foi feita com base na análise de conteúdo seguindo a proposta de Bardin (2011), tendo com base na fundamentação teórica dos conteúdos que basearam essa pesquisa. Assim, esta análise de conteúdos tentou buscar dentro dos contextos situacionais e de fala todos os significados e intenções pretendidas pelos entrevistados. Com isso, chegou-se a uma quase perfeita representação do contexto geral que foi estudado.

Este estágio para analisar os dados recolhidos ao longo do estudo foi importante, pois deu suporte para todas as outras etapas previstas pelo método. Ao compreender os dados sob a luz da teoria, chegou-se a uma tradução da realidade organizacional estudada e isso permitiu uma mais ampla gama de sugestões, bem como um melhor desenvolvimento das versões pensadas para o artefato. Da mesma forma, para a etapa de avaliação, houve mais uma rodada de análise de dados, dessa vez combinando os dados obtidos nos processos anteriores com aquela nova leva que foi apresentada pelos especialistas que avaliaram a solução sugerida. A seguir, cada uma dessas fases será detalhada com uma descrição dos procedimentos e achados, uma vez que todas elas geraram conhecimento e culminam com o artefato que é a contribuição deste estudo aplicado. 


\section{Consciência do problema}

A consciência do problema teve início entendendo o caso da empresa, depois foi realizada uma revisão da literatura e a coleta dos dados iniciais para que fosse possível seguir para a fase seguinte na busca da construção do artefato.

\subsection{Histórico da empresa}

A DOCE SABOR nasceu em 1991 e tinha por atividade a distribuição de matérias primas para indústrias de alimentos no Rio Grande do Sul. Em 1994 foi iniciada a produção do refresco em pó pela empresa. Em 1998, a empresa passou a se chamar DOCE SABOR, mesmo ano em que foi construído um novo parque industrial. No ano de 2000 foi conquistada a certificação ISO 9001. Em 2005 foi construído um novo prédio fabril com preceitos sustentáveis e, em 2011, foi inaugurada a DOCE SABOR Nordeste.

Em 2017 foi lançada a loja online da empresa, um canal direto com o consumidor, sendo que a loja online atualmente tem pouca relevância comercial. Sua governança corporativa possui uma estrutura com conselho de família, conselho de administração, conselho de acionistas, consultorias externas e compliance.

Atualmente, a empresa possui duas unidades, uma no Rio Grande do Sul e outra em Pernambuco. São 33,5 mil metros quadrados de área construída. A produção alcança 2,6 milhões de quilos produzidos mensalmente. São atendidos mais de cinquenta países. O portfólio possui em torno de 200 SKUs. A DOCE SABOR possui duas certificações, a ISO 9001 e a FSSC 22.000 .

A empresa produz e comercializa sete categorias de produtos: o refresco em pó; balas de goma, pastilhas e mini pastilhas; mini chicletes drageados e chicletes recheados; balas de gelatina; marshmallow; e canudos e fitas de alcaçuz. Segundo dados da Associação Brasileira da Indústria de Chocolates, Amendoins e Balas (ABICAB), a DOCE SABOR é a maiores fabricantes de pastilhas da América Latina (http://www.abicab.org.br, recuperado em maio, 2021). A empresa exporta para mais de 50 países. A sua relação com a sustentabilidade está na incorporação dos seguintes Objetivos de Desenvolvimento Sustentável (ODS) da ONU: ODS 8 - Trabalho decente; ODS5 - Igualdade de gênero; e ODS 3 - Saúde e bem-estar. 


\subsection{Entendendo a transformação digital da DOCE SABOR}

Com base no referencial teórico, foram realizadas entrevistas com gestores da empresa para compreender melhor o estágio da TD da DOCE SABOR e para obter subsídios para o desenvolvimento do artefato. Os encontros foram realizados no período compreendido entre outubro do ano de 2020 até início de março de 2021. Por conta da impossibilidade do encontro presencial devido a Pandemia do COVID 19, todas elas foram realizadas por videoconferência por meio da plataforma Teams®.

Os gestores destacaram que um dos primeiros passos para a jornada de transformação digital da DOCE SABOR foi dado em 2020, através da implementação de um Comitê de Transformação Digital (CTD), onde se começou pela rediscussão do propósito e valores da organização. Para o Comitê de transformação digital foi sugerida a revisão dos valores da empresa, conforme segue: jeito simples de ser e agir, respeito e dedicação às pessoas, colaboração e "mão na massa", criatividade para encantar e "jogo limpo".

Para a transformação digital da Doce Sabor foram estabelecidos pela empresa cinco premissas para a preparação dessa transformação: (i) alinhamento da estratégia de transformação do negócio aos objetivos da empresa; (ii) investimentos em tecnologias certas; (iii) transformação de ideias em ações; (iv) garantia que todos os envolvidos entendam o processo de transformação; (v) atualização contínua das estratégias digitais.

Foi estabelecida, também, uma jornada para alcançar a transformação digital que é: (i) revisão do propósito; (ii) desafio do modelo de negócios; (iii) construção em conjunto com as equipes; (iv) engajamento total e lidar com as "dores" temporárias; (v) cuidado com as "armadilhas tecnológicas". Para ser possível o alcance da transformação digital, identificaram a necessidade de criar uma equipe de orientação, ou seja, encontrar um líder, criar equipes multifuncionais, criar uma equipe de orientadores, nunca parar de aprender e buscar experts em trabalho com dados.

Por fim, a DOCE SABOR estabeleceu um processo a ser seguido, que começa por entender onde a empresa está, priorizando em tornar a empresa mais colaborativa, buscando agilidade, cocriação e inovação. Os gestores da empresa acreditam que o melhor caminho é adquirir ferramentas tecnológicas já prontas e existentes no mercado em vez de se dedicarem a criarem eles mesmos ferramentas tecnológicas. 


\section{Sugestão de artefato}

Nesta etapa, antes de começar o real desenvolvimento da solução, pensou-se também em qual seria o melhor tipo de artefato para o problema em questão. Com o respaldo da teoria e os dados obtidos, optou-se pela criação de um framework que conseguisse contextualizar as mudanças necessárias no cenário já existente dos processos dos times. Essa decisão funcionou como norteadora dos passos no momento do desenvolvimento.

A partir disso, tomou-se como base os principais conceitos apresentados na literatura, bem como os principais pontos apontados pelos executivos da empresa como basilares para o processo de transformação digital, quais sejam: diferença entre estratégia de Tecnologia da Informação (TI) e estratégia de Transformação Digital (TD); elementos essenciais para o processo de TD e; quais as fases inerentes ao processo de TD.

\section{Desenvolvimento}

A partir do direcionamento de uma possível solução dentro da etapa de sugestão, partiuse para o desenvolvimento de um artefato que pudesse dar conta desta questão e representar isso da melhor forma. Segundo Manson (2006), na DSR o artefato criado deve ser um conhecimento aplicável que possa solucionar problemas ou mesmo otimizar processos existentes. Com esta definição em mente, tentou-se gerar aqui uma reorganização das atividades nos diferentes estágios do ciclo de projetos. Assim, a versão "1" do artefato foi gerada pensando num framework que pudesse funcionar como guia contemplando as etapas para a implementação da Transformação Digital, conforme ilustrado na figura 3.

\section{Figura 3.}

Versão 1 do Framework

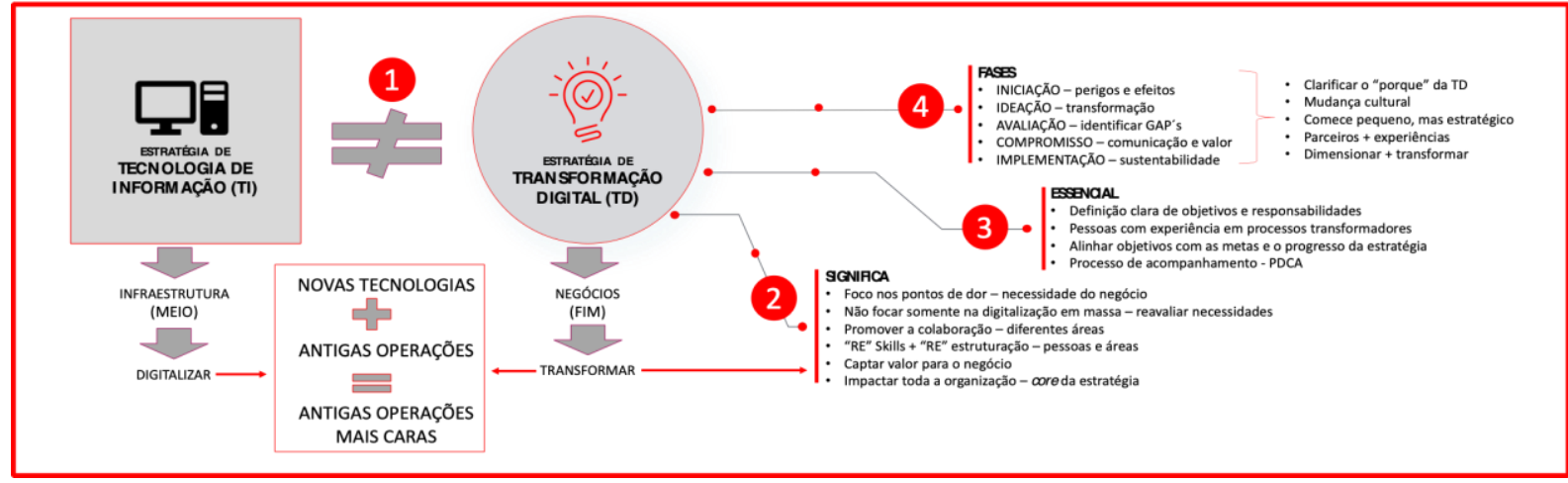

Fonte: Elaborado pelos autores (2021). 
Na versão "1" propõe-se, primeiramente, reforçar a (1) diferença entre estratégia de TI e estratégia de TD, haja visto a constante confusão entre os dois conceitos. Para tanto, conforme postulado por Matt et al. (2015), a estratégia de TD deve envolver a transformação do negócio (produtos, processos e aspectos organizacionais) através das novas tecnologias. Ao passo que a estratégia de TI visa a gestão da infraestrutura (meio). Desta forma, faz-se necessário uma transformação no modelo de negócios (operação), ou seja, não se trata simplesmente de embarcar novas tecnologias - sob pena de resultar em "operações antigas, mais caras". Conforme recomendado por Koeleman et al. (2019), foi apontado as (2) práticas que as organizações que implementaram o processo de TD tinham em comum. Também foi destacado que é (3) essencial haver a atribuição de responsabilidades adequadas e claras para a definição e implementação de uma estratégia de transformação digital, sob pena de as organizações perderem seu escopo e encontrarem dificuldades operacionais, conforme sugerem Koeleman et al. (2019) e Matt et al. (2015). Por fim, seguindo a recomendação de Liu et al. (2011), destacaram-se as fases inerentes ao processo de TD.

Com uma proposta definida para o que serviria de solução ao problema identificado, foi realizado o primeiro ajuste no artefato. Essa decisão foi fruto da discussão entre os autores e os executivos da empresa. Foi identificado a necessidade de considerar a conexão com o mercado, ou seja, um olhar de fora para dentro. Também foi apontado a necessidade de apontar quais seriam os possíveis caminhos a seguir, bem como as respectivas mudanças resultantes deles. Diante deste contexto, foi desenvolvido a versão " 2 " do framework.

Onde foi proposto a inclusão dos pontos mencionados como necessários e complementares a versão anterior. Para tanto, conforme postulado por Liu et al. (2011), a TD passa por uma integração de tecnologias digitais e processos de negócios em uma (5) economia digital. Neste sentido, Ziyadin et al. (2020) complementam que o uso de tecnologias emergentes pode mudar radicalmente os modelos de negócios das empresas - o que vai impactar em mudanças nas áreas de operações, produto e marketing. Essas (6) mudanças esperadas, conforme sugere Matt et al. (2015), poderão ocorrer de forma limitada (integrando novas operações às estruturas corporativas já existentes - caminho defensivo) ou substancial (criando uma subsidiária dentro da própria organização - caminho ofensivo). E, a seguir, passou-se a avaliação do artefato. 


\section{Avaliação}

A etapa consecutiva ao desenvolvimento é a de avaliação do artefato. Neste estágio, busca-se uma validação do que está sendo proposto através de um processo rigoroso de verificação do artefato no ambiente para o qual foi projetado e como ele pode chegar às soluções para as quais foi proposto (Lacerda et al., 2013).

\section{Quadro 2.}

Participantes do Grupo Focal de Aprovação do Framework de TD

\begin{tabular}{|c|c|c|}
\hline Participante & Nome & Cargo/função \\
\hline P1 & Executivo 1 & Diretor Comercial e Sócio fundador da empresa \\
\hline P2 & Executivo 2 & Conselheira de administração \\
\hline P3 & Executivo 3 & Gerente de Marketing \\
\hline P4 & Executivo 4 & Gerente de Projetos \\
\hline P5 & Executivo 5 & International Trader \\
\hline
\end{tabular}

Fonte: Elaborado pelos autores (2021).

Nesta etapa foi apresentado a versão "2" do framework em um grupo focal composto pelos executivos da DOCE SABOR, conforme quadro 2, e integrantes do comitê de TD da empresa, onde ela foi aprovada. Entretanto, durante a discussão, o CEO destacou a importância de considerar o impacto do processo de TD na operação e no negócio. A figura 4 traz o framework final. 


\section{Figura 4.}

Versão Final do Framework

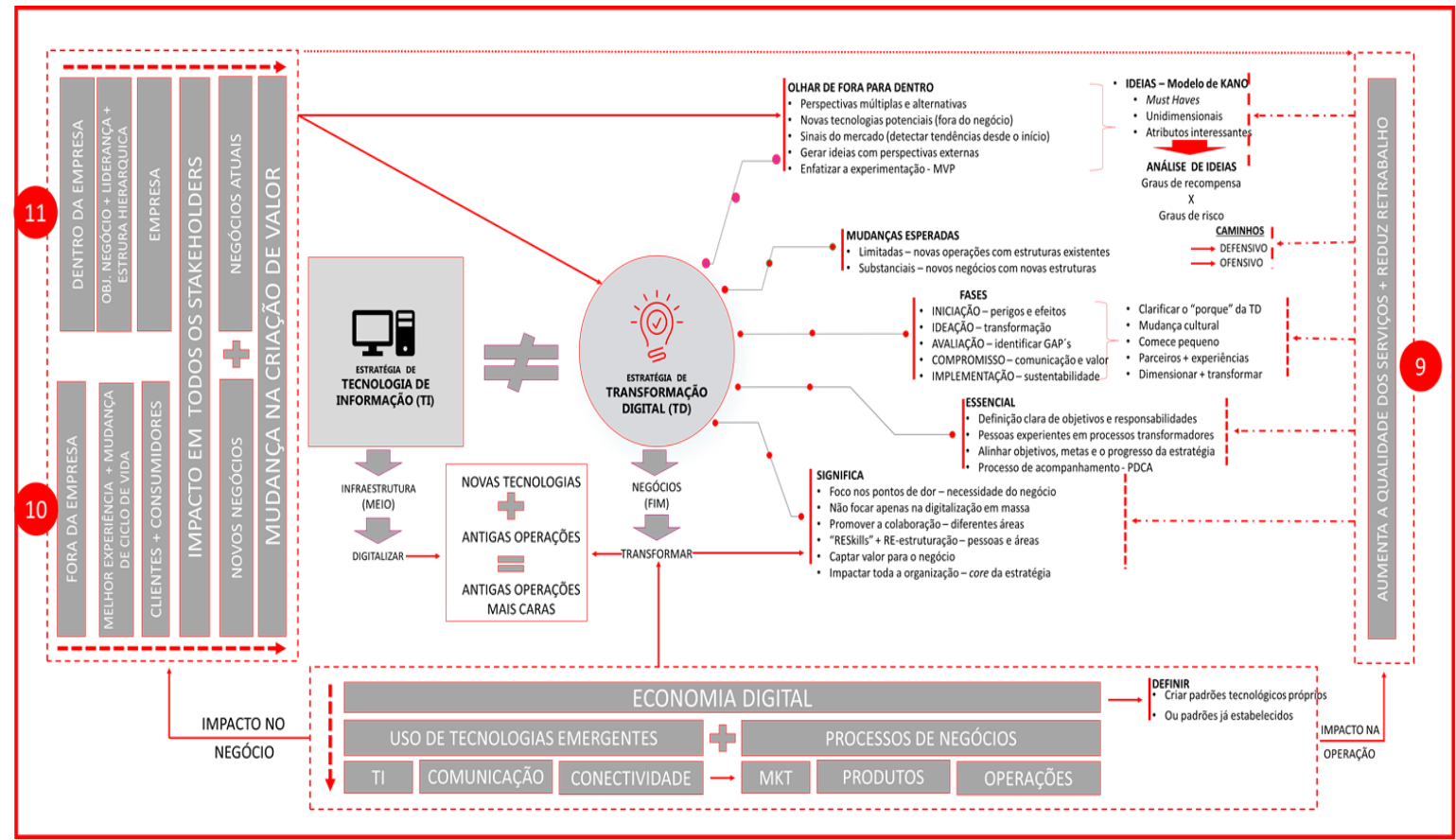

Fonte: Elaborado pelos autores (2021).

Diante disso, os autores mapearam os tópicos sugeridos na literatura, o que resultou na versão final do framework. Nesta nova reorganização, denominada "versão final do Framework", cabe explicar os elementos que foram agregados no framework. Primeiramente, entende-se que as etapas anteriores (ilustradas nas versões 1 e 2) têm impacto direto na (9) operação, uma vez que é recomendável que a implementação de casos de uso digital promova a colaboração entre os vários grupos e pessoas que colaboram com a organização, reduzindo retrabalhos e aumentando a qualidade de determinados serviços, conforme sugerem Koeleman et al. (2019). Todas essas mudanças estão traduzidas e ilustradas na figura 4.

Por fim, conforme Hess et al. (2016), a influência da transformação digital implica aspectos organizacionais (10) externos como a melhoria da experiência do cliente e todo o seu ciclo de vida e (11) internos que tem impacto sobre os objetivos do negócio e a liderança.

Após a finalização desta versão, ela foi submetida a apreciação da empresa, sendo aprovada - uma vez que cumpriu com o seu objetivo em apresentar um framework contemplando as etapas necessárias para a implementação da transformação digital da DOCE SABOR. 


\section{Conclusão}

O presente artigo aplicado apresentou um framework (figura 4) contemplando as etapas necessárias para a implementação da transformação digital na empresa DOCE SABOR. Ao longo do texto foi possível detalhar o passo-a-passo para se chegar neste resultado seguindo o método do DSR. Dessa forma, o artigo apresenta contribuições teóricas e práticas.

No que tange as contribuições teóricas, foram apresentados uma revisão de literatura atual sobre transformação digital, uma integração deste tema com estratégia. Além disso, as etapas do DSR geram conhecimentos e insights que corroboram com os dados teóricos descritos, na otimização das etapas de uma transformação digital na indústria estudada.

Como contribuição práticas e gerenciais, o principal entregável do artigo é o framework em si, que pode contribuir para o processo de inovação da empresa na medida que também irá influenciar de forma estratégica na implementação do processo de transformação digital. Na medida em que contempla um passo a passo que pode ser utilizado por organizações que se deparam com o desafio de transformar-se digitalmente. Isso representa uma vantagem competitiva importante em uma indústria onde atuam grandes players com produtos muito parecidos, especialmente, como a indústria de candies.

Por fim, afirma-se aqui que há etapas seguintes e pertinentes para o uso e aplicação desses recursos advindos das trocas comunicacionais que devem ser estudadas e testadas dando continuidade a este estudo.

A principal limitação deste estudo foi o fato de ter sido executado durante a pandemia de COVID-19 entre os anos de 2020 e 2021. Com isso, muitas das etapas de execução do método precisaram sofrer algumas adaptações, mas sem prejuízo no uso da DSR. Como sugestão de estudos futuros, propõe-se a aplicação do framework em outras empresas e modelos de negócios, para o seu aprimoramento, bem como a realização de estudos desta natureza em outros tipos de indústria, para validar ou aprimorar o framework apresentado.

\section{Referências}

Anderson, T., \& Shattuck, J. (2012). Design-based research: A decade of progress in education research? Educational Researcher, 41(1), 16-25. doi: https://doi.org/10.3102\%2F0013189X11428813

Azhari, P., Faraby, N., Rossmann, A., Steimel, B., \& Wichmann, K. S. (2014). Digital transformation report 2014. Eichenzell, Germany: Neuland GmbH \& Co. KG. Bardin, L. (2011). Análise de conteúdo. São Paulo: Edições 70. 
Barriball, K. L., \& While, A. (1994). Collecting data using a semi-structured interview: A discussion paper. Journal of Advanced Nursing-Institutional Subscription, 19(2), 328335. doi: https://doi.org/10.1111/j.1365-2648.1994.tb01088.x

Endres, H., Stoiber, K., \& Wenzl, N. M. (2019). Managing digital transformation through hybrid business models. Journal of Business Strategy, 41(6) 49-56. doi: https://doi.org/10.1108/JBS-07-2019-0142

Freitas, J. C. S., Jr., Machado, L., Klein, A. Z., \& Freitas, A. S. (2015). Design research: Aplicações práticas e lições aprendidas. Revista de Administração FACES Journal, 14(1), 95-116. doi: https://doi.org/10.21714/1984-6975FACES2015V14N1ART1999

Gobble, M. M. (2018). Digital strategy and digital transformation. Research-Technology Management, 61(5), 66-71. doi: https://doi.org/10.1080/08956308.2018.1495969

Hanelt, A., Bohnsack, R., Marz, D., \& Marante, C. A. (2021). A systematic review of the literature on digital transformation: Insights and implications for strategy and organizational change. Journal of Management Studies, 58(5), 1159-1197. doi: https://doi.org/10.1111/joms.12639

Hess, T., Matt, C., Benlian, A., \& Wiesböck, F. (2016). Options for formulating a digital transformation strategy. MIS Quarterly Executive, 15(2), 123-139. doi: https://doi.org/10.7892/BORIS.105447

Koeleman, J., Ribeirinho, M. J., Rockhill, D., Sjödin, E., \& Strube, G. (2019, August). Decoding digital transformation in construction. Capital Projects \& Infrastructure Practice.

Lacerda, D. P., Dresch, A., Proença, A., \& Antunes, J. A. V., Jr. (2013). Design science research: Método de pesquisa para a engenharia de produção. Gestão de Produção, 20(4), 741-761. doi: https://doi.org/10.1590/S0104-530X2013005000014

Leipzig, T. von, Gamp, M., Manz, D., Schöttle, K., Ohlhausen, P., Oosthuizen, G., Palm, D., \& Leipzig, K. von (2017). Initialising customer-orientated digital transformation in enterprises. Procedia Manufacturing, 8, 517-524. doi: https://doi.org/10.1016/j.promfg.2017.02.066

Liu, D. Y., Chen, S. W., \& Chou, T. C. (2011). Resource fit in digital transformation: Lessons learned from the CBC Bank global e-banking project. Managing Decision, 49(10), 1728-1742.

Manson, N. J. (2006). Is operations research really research? Orion, 22(2), 155-180. doi: https://doi.org/10.5784/22-2-40

Margiono, A. (2020). Digital transformation: Setting the pace. Journal of Business Strategy, 42(5), 315-322. doi: https://doi.org/10.1108/jbs-11-2019-0215

Matt, C., Hess, T., \& Belian, A. (2015). Digital transformation strategies. Business Information and System Engineering, 7(5), 339-343. 
Singh, A., Klarner, P., \& Hess, T. (2020). How do chief digital officers pursue digital transformation activities? The role of organization design parameters. Long Range Planning, 53(3). doi: https://doi.org/10.1016/j.lrp.2019.07.001

Vaishnavi, V., Kuechler, B., \& Petter, S. (Eds.). (2019, June). Design science research in information systems, 1-62. Retrieved November 8, 2021, from http://www.desrist.org/design-research-in-information-systems/

Vial, G. (2019). Understanding digital transformation: A review and a research agenda. The Journal of Strategic Information Systems, 28(2), 118-144.

White, N. (2020). 7 Tenets of an effective digital transformation strategy. Parametric Technology Corporation - PTC.

Ziyadin, S., Suieubayeva, S., \& Utegenova, A. (2020). Digital transformation in business. In S. I. Ashmarina, M. Vochozka, \& V. V. Mantulenko (Eds.). Digital age: Chances, challenges and future (pp. 408-415). Cham, Switzerland: Springer. 